\title{
A VISIBIUDADE DO TRABALHO DAS MULHERES TICUNAS DA AMAZÔNIA
}

\author{
IRAILDES CALDAS TORRES \\ Universidade Federal do Amazonas
}

\begin{abstract}
Resumo:Este artigo se ocupa de uma análise do artesanato indígena da Amazônia, confecciona do pelas mulheres tic unas, o qual se apresenta como um produto importante no desenvolvimento sustenta do da comunida de rural Bom Caminho, no estado do Amazonas. Tratase de um coteja mento de dados observa dos e coleta dos no processo de consultoria realizada ao Sebrae/Amazonas no ano de 2004. Mostra o trabalho das mulheres como o elemento ordenador da economia doméstica na etnia ticuna, sob o primado de uma divisão sexual do trabalho que credita a elas responsabilidade maior pela manutenção da família.
\end{abstract}

Palavras-chave: trabalho; mulheres tic unas; etnicidade; Amazônia.

Nas soc iedades indígenas da Amazônia, a família e as relações que dela resultam constituem-se no elemento organizador da economia. A divisão sexual do trabalho é o suposto da produção e tem nas a tividades femininas o ponto basilarda organização do trabalho. Na etnia ticuna da Amazônia brasileira a mulher é preparada para realizar o trabalho de artesã. A menina quando atinge a menarca é submetida a um noviciado moçangol. Ela fica mais de 30 dias isola da num determina do local sem vero sol. Somente a mãe ou a irmã ma is velha têm a a utorização do pajé ou xamã para entrarno local, darIhe a limento e a uxiliá-la na higiene corporal. A menina entra em rec lusã o para a perfeiç oar as prendas doméstic as e a prendera fazer os utensílios que irá utiliza rna sua casa apóso casamento, depois de passar pelo ritual da menina-moça.

A moça só estará apta para casar quando souber fazer vários objetos e prendas domésticas, pois "para ser digna de ter um marido bom caça dor uma mulher deve saber fabricar uma louça de qualidade para cozinhar e servir a sua caça". ${ }^{1}$ Nenhum homem desposaria uma moça que não saiba fazer nada, considerando-se que "mulheres incapazes de fazer louça seriam criaturas malditas". ${ }^{2}$ Além de a mulher saber tratar 0 peixe, cozinhar e lidar com os encargos da casa, rea liza ta mb ém um tra ba lho a rístic o de altíssima qualidade e fina sensibilidade.

2 LÉVI-STRAUSS, 1985, p. 33. 
Ta mbém o menino é submetido a esse processo de aprendizagem, já que, para assumir o compromisso matrimonial, ele deve primeiro saberfazer um mapa para pescar, caçar e se apropriar de todo o serviço reservado aos homens. 0 processo de iniciação ou noviciado envolve vários passeios dos meninos com alguns adultos na floresta. Os adultos a rregimentam todos os meninos da comunidade em idade de iniciação (puberdade) e os levam para passear no mato. Ali os meninos a prendem a ser guerreiros, caçar e enfrentara mata fechada.

$\mathrm{Na}$ sociedade tic una, toda a lógica subjacente ao sistema que informa as sçõese o comportamento indígena em suas relações sociais, particularmente no que se refere à quelas entre homens e mulheres, reside no modo como os sujeitos perc ebem e orga niza $\mathrm{m}$ o seu universo cultural. Nesse universo, as diferenças centra is entre os gêneros servem como baliza para determinar as posições ocupadas por eles no contexto social onde atua $m .{ }^{3}$ Nessa etnia as fundações de vida e de morte, as ações do cotidiano, 0 traba lho e as relações socia is são recorta dos pelo simbolismo. Homens e mulheres desempenham papéis sociais baseados em valores mitológicos que constituem o seu acervo cultural. Entre a mulher e a olaria, por exemplo, paira um simbolismo da feminilidade. Segundo Lévi-Strauss, "é à índia que compete fabricar os recipientes de cerâmica e servir-se deles, porque a argila de que são feitos é feminina como a terra". ${ }^{4}$ Guardadas todas as situações de discriminação e exploração da mulher na sociedade ticuna, pode-se dizer que elas são parte integrante desse sistema simbólico. 0 trabalho é visto como um fator de maturação e desenvolvimento social para as mulheres, que só são desobrigadas das atividades laborais aos 60 anos de idade, momento em que elas vão assumir outras funções como conselheiras, dand o palpites sob re o que fazer em determina das situa ções e até impedindo as guerras.

O aspecto social do trabalho sustenta-se numa ética de solidariedade e relações com a natureza que presc inde das determinações derivadas das grandezas socia Imente estabelecidas, querseja no âmbito do lucro e da renda da terra, quer seja no aspecto do salário ou de outros tipos de troca econômica. 0 ajuri é o tipo de trabalho coletivo que mobiliza várias famílias para ajudar no plantio ou na colheita agrícola de uma outra família que se encontra em dificulda des e sem recursos. É o que nos explic a Arthur Reis ao a firmar que "o trabalho coletivo, os adjutórios que mobilizam as pequenas coletividades na obtenção de maior rendimento na obra em que um, sem mais recursos, não pode executar tudo, o ajuri, é de origem indígena". ${ }^{5}$ São as mulheres que organizam o ajuri depois de terem percebido as dificuldades de determinada família que necessita de ajuda. A família que recebe a ajuda deverá prover somente a alimentação aos traba lha dorese alguma gratific ação com farinha ou outro produto fabricado pelo próprio coletivo de trabalhadores. Posteriormente, essa prática do trabalho coletivo passou a ser remunerada em algumas comunidades caboclas, pois essas comunidades sempre mantiveram um padrão de vida baseado na agricultura de subsistência nas terras de várzea que obedecem às leis de enchente e vazante dos rios. Toma-se necessário, em alguns casos, contratar trabalhadores para evitar a perda da colheita.

O significado social das atividades das mulheres é bem mais diversificado e participante do que geralmente possa mos supor. Além de elas realizarem o importante trabalho de preparo do plantio, participam também das atividades de colheita de malva,

\footnotetext{
${ }^{3}$ Maria Angélic a MAUÉS, 1993.

${ }^{4}$ LÉVI-STRAUSS, 1985, p. 28.

${ }^{5}$ REIS, 1966, p. 45.
} 
piaça va e lavagem de juta, considera do trabalho pesado. No período colonial homense mulheres trabalharam na produção das drogas do sertão sob o jugo do trabalho forçado. Construíram "intensa lavoura de cacau, de algodão, de café, de outras espécies comerciáveis". ${ }^{6}$ No século XIX, Lourenço da Silva Araújo e Amazonas admoestava a sociedade branca a firmando que as mulheres índia s não diferia m em qualida des mora is em relação aos homens. Dotadas de um talento natural que parecia suprir a falta de educação formal, "as mulheres desempenham seu sublime ministério sobre a terra em companhia do homem [...], porsua temura de indígena a o pé do berço de sua prole, e pela instintiva e angélica devoção em compartir a dor do que sofre". 7

Ainda é bem visível esse tipo de divisão social do trabalho na etnia ticuna. 0 artesanato, a arte da olaria e toda a produção realizada pelas mulheres possuem um c unho soc ial signific a tivo. Na comunida de Bom Caminho a comercia liza ção do a rtesa na to tem-se constituído numa fonte de renda às famílias. A Associação de Mulheres Artesãs Ticunas de Bom Caminho (AMATU) é um exemplo de entidade social que organiza e encaminha os produtos fabricados pelas mulheres para o mercado consumidor. Com a venda desses produtos as mulheres garantem o sustento de suas famílias. 0 trabalho de a rtesã constitui-se na arte da perfectibilidade da obra. Tanto a ola ria quanto a tecelagem representam uma das maiores artes da civilização. Lévi-Strauss ressalta que, "nas sociedades européias tradicionais, o ofício de oleiro era muitas vezes exercido por um grupo, mais do que por um indivíduo isola do". ${ }^{8}$ Nas sociedades dos povos da floresta e das savanas da América tropical a arte da olaria é realizada por mulheres, que podem formar grupos para esse tipo de ofício ou desempenhá-lo individualmente. Também na África a olaria é um ofício circunscrito às mulheres, tendo as etnias às vezes funções artesanais distintas no âmbito da olaria e da forja, assemelhando-se às castas. Para os a meríndios, sobretudo os jíva ros e os dessa nas da Ama zônia, a ola ria assume fundamental importância na divisão social do trabalho. Lévi-Strauss explicita que, "pa ra se dar conta da passagem da natureza à cultura, do cru ao cozido, um conjunto acentua o fogo de cozinha, outro a olaria, cujo emprego culinário supõe adquirido o fogo doméstic $0 " .{ }^{9}$

As mulheres deveriam se apropriar desse ofício da arte do intelecto com exímia responsabilidade. Todo cuidado era pouco para não incorrer em qualquer deslize que pudesse a muinar o objeto em processo de fabricação. Além da atenção minuciosa e da paciência necessária a o processo de fabric ação dos produtos, eram nec essá ria s ta mbém a destreza dos dedos alongados e a delicadeza no manejo das peças. A percepção cognitiva era indubitavelmente a matriz de todo o processo de fabricação. Tudo deveria ser muito preciso, desde o tipo de argila e a textura da massa, a té o ponto do forno e do cuidado para não dourar demais e nem de menos. Mantida a acuidade da percepção e da arte do ornato, as mulheresmostrar-se-iam capazes de fabricarpeças de reconhecida habilidade e criação artística.

Deve-se notar que a divisão sexual do trabalho não esgota a noção de relações de trabalho transpassadas pelo corte de gênero. As relações de trabalho sexuadas comportam construções cultura is e históric as interd ependentes e complementares. Pa ra Elizabeth Souza-Lobo, "as relações entre homens e mulheres são vividas e pensadas enquanto relações entre o que é definido como masculino e feminino: os gêneros". ${ }^{10}$ É

${ }^{6}$ REIS, 1966, p. 138.

${ }^{7}$ AMAZO NAS, 1984, p. 24-25.

${ }^{8}$ LÉVI-STRAUSS, 1985, p. 17.

${ }^{9}$ LÉVI-STRAUSS, 1985, p. 174

${ }_{10}$ SO UZA-LOBO, 1992, p. 260. 
a ssim que a divisão sexual do trabalho entra em inflexão enquanto conceito absoluto das determina ções entre os sexos, passando a serum dos muitos locus das relações de gênero. Gênero é uma categoria a nalítica que constrói uma relação social-simbólica, sem estabelecer uma mecânica de determinação. Do mesmo modo, gênero e etnia são conceitos que nasceram de um mesmo esforç 0,0 de a fastar-se de idéias e estereótipos que fazem da biologia o determinante de relações soc ia is. ${ }^{11}$ Esses do is conc eitos rela ciona is só têm sentido se forem tomados dentro de relações socia is envolvendo pessoas que se diferenciam, confrontando formas diferentes de identidadesque se constroem nas relações de confronto e de convivência. ${ }^{12}$

Bom Caminho, solo da experiência de trabalho artesanal das mulheres da nação tic una, objeto deste estudo, é uma comunida de rural do município de Benja min Constant, inc rusta do na mesorregião do Alto Solimões, esta do do Amazonas. Loc aliza do no extremooeste desse esta do e distante $1.118 \mathrm{~km}$ da capital Manaus, em linha reta, Benja min Constant se destaca pela inserção de populações indígenas em atividades econômicas sob a égide do desenvolvimento sustentável. O município possui uma área de $8.742 \mathrm{~km}^{2}$, com uma população estimada em 23.219 habitantes. A população masculina é de a proximadamente 11.973 , e a feminina, $11.246 .{ }^{13} \mathrm{~A}$ condição humana dos indígenas da etnia ticuna está diretamente relacionada à identidade regional, expressa na relação harmoniosa entre o homem nativo e a natureza. A relação de desequilíbrio com o meio ambiente começou a se estabelecer, segundo Djalma Batista, ${ }^{14}$ a partir da presença exógena na Amazônia.

A relação de trabalho do indígena se dá a partir da sua experiência com a terra, a floresta e os rios, que são os maiores referencia is de sua vida. Em tempos pretéritos e assaz anteriores à conquista portuguesa na regiã o (séc. XVII), a orga nização do traba lho e a divisão da produção, principalmente de alimentos, ga rantia m vida farta aos indígenas, que reservavam boa parte do seu dia para o lazer e a vida a prazível em família. Entre as populações indígenas a abundância de alimentos só era possível por causa do uso sustentável de todos os recursos natura is disponíveis, quando a caça e a pesca, a coleta e a agricultura, sobretudo na várzea, eram pratica das de a cordo com as leis de enchente e vazante daságuas. ${ }^{15}$

Hoje, os tempos são outros e os indígenas se vêem aviltados em sua condição de vida. A perda da lucrativida de do extra tivismo da borracha e a ausência de investimentos em polític as públic as nas áreas rura is contribuíram para a pauperiza ção da população local, cuja expecta tiva de vida é de 65,71 a nos e o IDHM é de 0,640 (é o 3.934ㅇ do Brasil). 0 artesanato, que é um produto importante na identidade tic una, potencia lmente capaz de impulsionaro desenvolvimento sustentado da comunidade em estudo, assumia forma individualiza da em sua produção e comercialização. A troca de produtos artesana is por roupas usadas e gêneros alimentícios não chegava a impactar a economia doméstica, embora contribuísse minimamente para minorar o estado de penúria dos indígenas.

A baixa lucratividade obtida na venda do artesana to no município de Benjamin Constant e/ou no município vizinho, Tabatinga, não compensava sequer o dispêndio de força física empregada na mão-de-obra, muito menos o trabalho cognitivo despendido na produção artística do produto. Algumas artesãs levavam seus produtos para serem

\footnotetext{
${ }^{11}$ Cristina WOLFF, 1999, p. 191.

${ }^{12}$ Maria Odila DIAS, 1994.

${ }^{13}$ Dados de 2000 do IBGE.

${ }^{14}$ BATISTA, 1976.

${ }^{15}$ Ira ild es TO RRES, 2005.
} 
comercia liza dos na cidade de Letícia, onde ta mbém não obtinham um preço justo, pois eram identificados como souveniers made in Colômbia. A presidente da AMATU, Rosa Chota, ${ }^{16}$ lembra que o baixíssimo preço dos produtos nem sempre cobria os gastos com o transporte (entrevista/2004).

A economia solidária foi a forma encontrada para gerar renda aos moradores da comunidade Bom Caminho. A economia solidária é um novo conceito que vem sendo construído no Brasil, de forma esparsa e difusa, desde a década de 1980. Trata-se de emp reendimentos a utogestioná rios que diferem do ca pita lismo, mas não so brevivem fora de uma economia mercantilista - entenda-se, fora de um sistema de compra e troca. ${ }^{17}$ É sobretudo a partir dosanos 1990 que a economia solidária passou a ganharvitalida de e visibilidade no Brasil. Algumas empresas que entraram em processo falimentar foram rea bilita das pelos próp rios tra ba lha dores, que passa ra m a a utogeri-las democratic a mente com participação nos lucros e nas decisões. Mas a economia solidá ria não se restringe à compra de ações das empresa sporparte dos trabalhadores diante da sucumbência dos negócios, atingindo sobremaneira a massa dos excluídos sociais.

Nezilda Culti ${ }^{18}$ sinaliza para o fato de que os exc luídos socia is despertaram para a realização de negócios comunitários para satisfazer suas necessidades e abrir novos caminhos na vida, pormeio do uso de suas próprias forças e recursos, associando-se a outrose orga niza ndo-se em grupos, a ssociaçõese coopera tivas. A cria ção da Associa ção de Mulheres Artesã s Tic unas de Bom Caminho, em 5 de dezembro de 1999, foi o ponto de partida para a potencialização da economia dos indígenas da referida comunidade. 0 artesanato apresentou-se como uma excelente altemativa para o desenvolvimento sustentável local. Para potencializar essa altemativa, fez-se necessária a realização de atividades de revitalização do produto artesanal, atra vés da capacitação das artesãs, pois o artesana to necessitava de um burilamento e refinamento que lhe imprimisse maior competitividade, necessária para acessar mercados exigentes e preocupados com a origem dos produtos. Essas ações foram desenvolvidas por técnicos do Sebrae do Amazonas, que não só ensinarama metodologia de intervenção do design como também realiza ram curso de associativismo.

0 a rtesa na to necessita va a liar a sensibilida de e a habilida de da a rtesã, na criação do belo, com o espírito do trabalho solidário e compartilhado voltado para o a tendimento de necessidades coletivas e individuais. Abrir-se-ia uma oportunidade ímpar de potencia liza ção e visibiliza ção do traba lho indígena no merc a do nacional e intema cional. As peças artesana is leva vam consigo os traços da cultura simbólica e associativista das mulheres tic unas da Ama zônia. É patente o fato de serem a s mulheres os sujeitos centra is na organização da economia doméstic a da etnia ticuna. Elas realizam, inclusive, um tipo de trabalho maispesado do que os homens, que é a preparação e capinação do roçado para o plantio a grícola. São elas que se ocupam da limpeza do campo sob a técnica da capinação e da coivara, que consiste na queimada do matagal retirado, num processo de adubação da terra para o plantio. ${ }^{19}$ São as mulheres que se ocupam do trabalho de

\footnotetext{
${ }^{16}$ Quando este trabalho foi realiza do, o SEBRAE solic itou a utoriza ção de Rosa Chota e Elizabeth Souza para citá-las (com seus nomes verda deiros) na pesquisa. Ao pesquisa dor Monteiro, já falecido, ta mbém foi solic ita da permissão para usaro seu nome, e a própria obra pública dele também justifica esse tratamento. Já no caso de outras indígenas associadas e citadas em trabalhos relaciona dos com o estudo e a intervenção a os quais este artigo se refere, preferiu-se usar inicia is ou nomes fictícios em respeito a os seus direitos de a nonimato.

${ }_{17}$ Paul SINGER, 2000.

${ }^{18}$ CULTI, 2002.

19 TORRES, 2005.
} 
fiar, bordar, tecer a rede de dormir e a rede de pesca; fazem o jamaxi, que é o utensílio utiliza do para iluminar a rede de pesca; fa zem abanosou leques, pa neiros pa ra o depósito de farinha, cestos, peneiras, bala ios; confeccionam o jirau para tratar o peixe; fabricam o seu próprio fogão de barro e o fomo de fazer farinha; tecem o tipiti, que é utilizado na fabricação de farinha; enfim, confeccionam vários outros implementos de cozinha com paciência, atenção e perfeccionismo (Mário Ypiranga Monteiro, entrevista/2001).

Para Lévi-Strauss, as mulheres indígenas da Amazônia "faziam uma cerâmica policromática de grande beleza e maestria [...]". ${ }^{20}$ Essa a ptidão técnica e a rtística é a companhada de uma inflexão signific ativa da mitologia do arco-íris. Para osínd iostic unas, o arco-íris é o senhor da argila de cerâmica. O método utilizado pelo herói para preparar sua pa leta produz a parentemente uma mistura parcial, dando à pintura dos instrumentos um aspecto fundido, semelhante às nuanças do arco-íris. É o aspecto dessa pintura a causa principal do saber relativo aos instrumentos que as mulheres não podiam ver. Ao longo do tempo esse mito acabou perdendo vigor a ponto de serem as próprias mulheres ticunas que realizam, hoje, a pintura policromática na cerâmica.

É p reciso desmistific ar as idéias que tendem a diminuire discriminar as mulheres no universo indígena. Elas desempenham um papel fundamental na tribo, sem o qual a economia doméstica não seguiria o seu curso normal. É fa to incontestá vel a luc rativida de do artesanato indígena de Bom Caminho, o qual beneficiou 136 famílias em 2001 e já gerou cerca de 991 empregos diretos sem a degradação do meio a mbiente. Atualmente a AMATU benefic ia diretamente seus 35 associados e ind iretamente 61 famílias na própria comunid a de e cinco fa mílias da comunida de de Porto Espiritual, to ta liza ndo 486 pessoas. Para Elizabeth Souza, ${ }^{21}$ membro da AMATU, a potenc ia liza ção do a rtesa na to tic una trouxe de volta o orgulho da sua origem, "elevou a a uto-estima indígena e trouxe uma perspectiva de vida melhor para todos" (entrevista/2004).

0 momento presente exige que o sujeito histórico, homem e mulher, crie novas oportunida des e formas de trabalho socialmente reinventadas e a uto-sustentá veis. Essa é a condição histórica de reinvenção da sobrevivência com o uso de novas técnicas de trabalho, em que as pessoas busquem a sua valoriza ção, a mpliem a sua capacidade e se redescubram condutoras da sua história.

\section{Referências bibliográficas}

AMAZONAS, Lourenço da Silva Araújo. Dicionário topográfico, histórico, descritivo do Alto Amazonas. Manaus: Grafima, 1984.

BATISTA, Djalma. O complexo da Amazônia: análise do processo de desenvolvimento. Prefá c io de Arthur Cezar Ferreira Reis. Rio de Janeiro: Conquista, 1976.

CULTT, Maria Nezilda. "O coopera tivismo popularno Bra sil: importância e representatividade". In: CONG RESSO EUROPEU DE LATINO AMERIC ANISTAS, 4., 2002, Amsterdã, Hola nda. Mimeo.

DIAS, Maria Odila Leite da Silva. "Novas subjetividades na pesquisa histórica feminista: uma hermenêutica das diferenças". Revista Estudos Feministas, v. 2, n. 2, p. 373-382, 1994.

${ }^{20}$ LÉVI-STRAUSS, 1991, p. 306.

${ }^{21}$ Ver nota 16. 
LÉVI-STRAUSS, Claude. A oleira ciumenta. Tradução: José Antônio Braga Femandes Dias. Lisboa: Edições 70, 1985.

O cru e o cozido. Tradução: Bea triz Perrone Moisés. São Paulo: Bra siliense, 1991.

MAUÉS, Maria Angélica Motta. Trabalhadeiras e camarados: relações de gênero, simbolismo e ritualização numa comunidade amazônica. Belém: Centro de Filosofia e Ciências Huma nas da UFPA, 1993.

REIS, Arthur Cézar Ferreira. Aspectos da experiência portuguesa na Amazônia. Manaus: Edições Govemo do Esta do do Amazonas, 1966.

SINGER, Paul. "Economia solidária: um modo de produção e distribuição". In: SINGER, Paul; SOUZA, André Ricardo de (Orgs.). A economia solidária no Brasil: a a utogestão como resposta a desemprego. Sã o Paulo: Contexto, 2000. p. 11-28.

SOUZA-LOBO, Elizabeth. "O trabalho como linguagem: o gênero do trabalho". In: COSTA, Albertina de O liveira; BRUSC HINI, Cristina (Orgs.). Uma questão de gênero. Rio de J a neiro: Rosa dos Tempos; Sã o Paulo: Fundação Carlos Chagas, 1992. p. 252-265.

TORRES, Iraildes Caldas. As novas amazônidas. Manaus: Editora da UFAM, 2005.

WOLFF, C ristina Sc heibe. Mulheres da floresta: uma história - Alto J uruá, Acre (1890-1945). São Paulo: Hucitec, 1999.

\section{The Visibility of Work among Ticuna Women in the Amazon}

Abstract: This paper a nalyzes the Amazon Indian craftsmanship, done by Tic una Women. Crafts are shown to be an important product in the strong positive development in the rural Amazon community. It works with data observed and collected in research done as a consultant for Sebrae/Amazonas in 2004. It shows how women work is a n organizing element of the domestic economy for the Tic una ethnic ity. A principal feature of the sexual division of labor places women as having more responsibility for fa mily maintenance.

Key words: Work; Tic una Women; Ethnic ity; Amazon. 